\title{
PENGEMBANGAN E-LEARNING MENGGUNAKAN ADOBE ANIMATE CREATIVE CLOUD DENGAN PENERAPAN METODE MULTIMEDIA DEVELOPMENT LIFE CYCLE
} (MDLC)

\author{
Ninuk Riswandari ${ }^{1}$, Nurma Yuwita ${ }^{2}$, Gatut Setiadi ${ }^{3}$ \\ 1),2)Universitas Yudharta Pasuruan, 3)IAI Sunan Kalijogo Malang \\ 1)ninuk@yudharta.ac.id, 2)nurma@yudharta.ac.id, 3)gatutxxx@gmail.com
}

\begin{abstract}
Abstrak. Materi pembelajaran akan lebih menarik minat belajar peserta didik jika disajikan secara interaktif, maka peneliti memanfaatkan sebuah aplikasi yakni Adobe Animate Creative Cloud untuk mengembangkan media pembelajaran interaktif, karena aplikasi ini merupakan salah satu aplikasi yang dapat digunakan untuk menggabungkan multimedia seperti gambar, audio, film, dan animasi. Sekolah yang menjadi tempat penelitian untuk pengembangan media pembelajaran interaktif keberagaman SARA adalah SMP Bhinneka Tunggal Ika yang terdapat di Desa Sengonagung, Kabupaten Pasururan. Berdasarkan hasil observasi diketahui: (1) kurikulum untuk kelas VII telah menggunakan kurikulum 2013, (2) belum adanya media pembelajaran interaktif PPKn dengan memuat materi pelajaran tentang keberagaman SARA pada kelas VII, (3) terdapat sebuah laboratorium komputer yang memadai untuk pembelajaran dengan menggunakan media pembelajaran interaktif. Metode yang digunakan untuk mengembangkan media ini adalah metode Multimedia Development Life Cycle (MDLC). Tujuan dari penelitian pengembangan media pembelajaran keberagaman SARA yaitu: 1) memberikan media pembelajaran interaktif tentang keberagaman SARA berbentuk flash dengan format (.exe); 2) memudahkan guru dalam menyampaikan materi keberagaman SARA dan juga memudahkan peserta didik dalam memahami keberagaman SARA. Penelitian ini menggunakan pendekatan interpretatif-konstruktivis, sedangkan metodologi yang digunakan kualitatif deskriptif dengan metode pengambilan sampel purposive sampling. Metode dalam pengumpulan data yaitu wawancara mendalam, observasi dan dokumentasi. Media pembelajaran interaktif yang dikembangkan di dalamnya memuat tentang 4 bagian yakni 1) Kompetensi Dasar, 2) Bahan Ajar, 3) Soal Latihan, dan 4) Materi Pendukung. Selanjutnya media pembelajaran interaktif keberagaman SARA telah melalui beberapa penilaian dengan hasil Layak dan Baik, kemudian di kemas dalam bentuk DVD dengan format file (.exe), lalu didistribusikan kepada pengguna yakni guru dan peserta didik di SMP Bhinneka Tunggal Ika dengan tujuan agar dapat digunakan dalam pembelajaran PPKn khususnya tentang keberagaman SARA.
\end{abstract}

Kata Kunci: E-Learning, Aplikasi Adobe Animate Creative Cloud, Multimedia Development Life Cycle (MDLC)

Abstract. Learning materials will attract students' interest in learning if they are
presented interactively, so researchers use an application namely Adobe Animate
Creative Cloud to develop interactive learning media, because this application is one
application that can be used to combine multimedia such as images, audio, films, and
animation. The school that became the research site for the development of interactive
learning media for SARA diversity was the Bhinneka Tunggal Ika Junior High School 


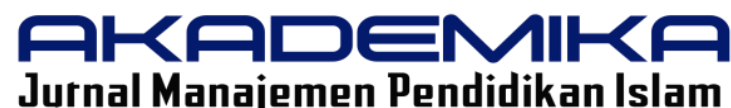

INSTITUT AGAMA ISLAM SUNAN KALIJOGO MALANG

P-ISSN 2622-9293 / E-ISSN 2721-9658

Volume 3 Nomor 1 Juni 2021

located in Sengonagung Village, Pasururan Regency. Based on the results of observations, it is known: (1) the curriculum for class VII has used the 2013 curriculum, (2) there is no interactive learning media for Civics by containing subject matter about racial diversity in class VII, (3) there is an adequate computer laboratory for learning using interactive learning media. The method used to develop this media is the Multimedia Development Life Cycle (MDLC) method which has 6 stages, namely 1) concept, 2) design, 3) collecting material, 4) assembly, 5) testing, and 6) distribution. The objectives of the research on the development of SARA diversity learning media are: 1) to provide interactive learning media about SARA diversity in the form of flash with the format (.exe); 2) make it easier for teachers to convey SARA diversity material and also make it easier for students to understand SARA diversity. This study uses an interpretive-constructivist approach, while the methodology used is descriptive qualitative with purposive sampling method. Methods in data collection are in-depth interviews, observation and documentation. The interactive learning media developed in it contains 4 parts, namely 1) Basic Competencies, 2) Teaching Materials, 3) Practice Questions, and 4) Supporting Materials. The interactive learning media has also gone through several feasibility validation assessments. Furthermore, the SARA diversity interactive learning media which has gone through several assessments with the results of Eligible and Good are packaged in the form of a DVD with a file format (.exe), then distributed to users, namely teachers and students at Bhinneka Tunggal Ika Junior High School with the aim that it can be used in teaching and learning activities. PPKn learning, especially about SARA diversity.

Keywords: E-Learning, Adobe Animate Creative Cloud Application, Multimedia Development Life Cycle (MDLC)

\section{PENDAHULUAN}

Media pembelajaran menjadi bagian yang penting dalam proses belajar mengajar, hal ini karena media pembelajaran bisa menjadi sarana yang dapat membantu guru dalam menyampaikan materi pelajaran kepada siswa. Media pembelajaran memiliki fungsi sebagai pembawa informasi dari sumber (guru) menuju penerima (siswa). Dengan menggunakan media pembelajaran yang tepat dan sesuai dengan materi pembelajaran, maka indikator pembelajaran akan dapat tersampaikan dengan baik. Media adalah semua bentuk perantara yang dipakai orang sebagai penyebar ide atau gagasan itu sampai pada penerima. Menurut Vaugan (2011: 1) multimedia adalah kombinasi teks, seni, suara, animasi, dan video yang dikirimkan oleh komputer atau sarana elektronik lainnya atau digital manipulasi. Dari pendapat tersebut dapat dipahami tentang pentingnya media pembelajaran sebagai sarana dalam menyampaikan ilmu pengetahuan kepada siswa, agar siswa dapat dengan mudah memahami semua ilmu yang disampaikan. Media pembelajaran selalu berkembang seiring dengan kemajuan teknologi pada setiap masanya. Pada masa sekarang teknologi komputer, 
laptop, notebook, smartphone, tablet menjadi alat yang dapat digunakan sebagai media pembelajaran melalui aplikasi yang dirancang khusus untuk sebuah proses belajar mengajar.

Media pembelajaran interaktif sangat menarik dari segi visual grafis, audio, dan animasinya, oleh sebab itu siswa akan lebih banyak berminat menggunakan media pembelajaran interaktif. Jika minat siswa muncul dalam sebuah pembelajaran, maka target pembelajaran akan dapat tercapai dengan baik. Selain itu di era kemajuan teknologi yang pesat pada masa sekarang hampir tiap sekolah telah memiliki laboratorium komputer.

Kurikulum 2013 mulai banyak diterapkan pada pendidikan formal, berangsur-angsur menggantikan KTSP 2006. Pada Kurikulum 2013 edisi revisi 2017 untuk mata pelajaran PPKn lebih menekankan pada pembelajaran yang mengacu pada genre teks, dan merupakan sintesis dari 3 pendekatan, yaitu: (1) pedagogi genre, (2) saintifik, dan (3) Content and language integrated learning (CLIL). Pendekatan tersebut digunakan guna mencapai indikator pembelajaran pada tiap Kompetensi Dasar (KD) yang berkaitan dengan materi ajar. Dengan penerapan kurikulum 2013 dan menggunakan pendekatan yang tepat dalam pembelajaran maka akan dapat meningkatkan kualitas kompetensi siswa dalam memahami materi pembelajaran dan juga kualitas karakter siswa.

Aplikasi Adobe Animate Creative Cloud merupakan aplikasi yang banyak digunakan oleh desainer web, karena mempunyai kemampuan yang lebih unggul dalam menampilkan multimedia, gabungan antara teks, gambar, grafis, animasi, suara, video serta interaktifitas user. Adobe Animate Creative Cloud termasuk program Aplikasi profesional yang digunakan untuk membuat animasi vektor dan bitmap yang sangat sesuai untuk membuat suatu situs web yang interaktif, menarik dan dinamis. Aplikasi ini berbasis animasi vektor yang dapat juga digunakan untuk menghasilkan $\mathrm{CD}$ pembelajaran interaktif. Adobe Animate Creative Cloud memiliki beberapa fitur unggulan, seperti Creative Cloud Libraries dan Adobe Stock Integration. Menurut Yuwita, dkk (2019) mengatakan bahwa media pembelajaran interaktif menggunakan aplikasi adobe animate creative cloud merupakan gabungan konsep pembelajaran dengan teknologi audiovisual yang mampu menghasilkan fitur-fitur baru yang dapat dimanfaatkan dalam dunia pendidikan.

Sekolah yang menjadi tempat penelitian adalah SMP Bhinneka Tunggal Ika yang terdapat di Desa Sengonagung-Pasururan. Tujuan dari penelitian pengembangan media pembelajaran keberagaman SARA yaitu: 1) memberikan media pembelajaran interaktif tentang keberagaman SARA berbentuk flash dengan format (.exe); 2) memudahkan guru dalam 
menyampaikan materi keberagaman SARA dan juga memudahkan peserta didik dalam memahami keberagaman SARA.

\section{Skema Penelitian}

Penelitian ini berangkat dari E-Learning menggunakan aplikasi Adobe Animate Creative Cloud yang menjadi alternatif aplikasi untuk dapat digunakan pada pembelajaran interaktif materi keberagaman SARA. Aplikasi Adobe Animate Creative Cloud merupakan inovasi baru. Peneliti menganalisis media interaktif keberagaman SARA menggunakan metode Multimedia Development Life Cycle (MDLC).

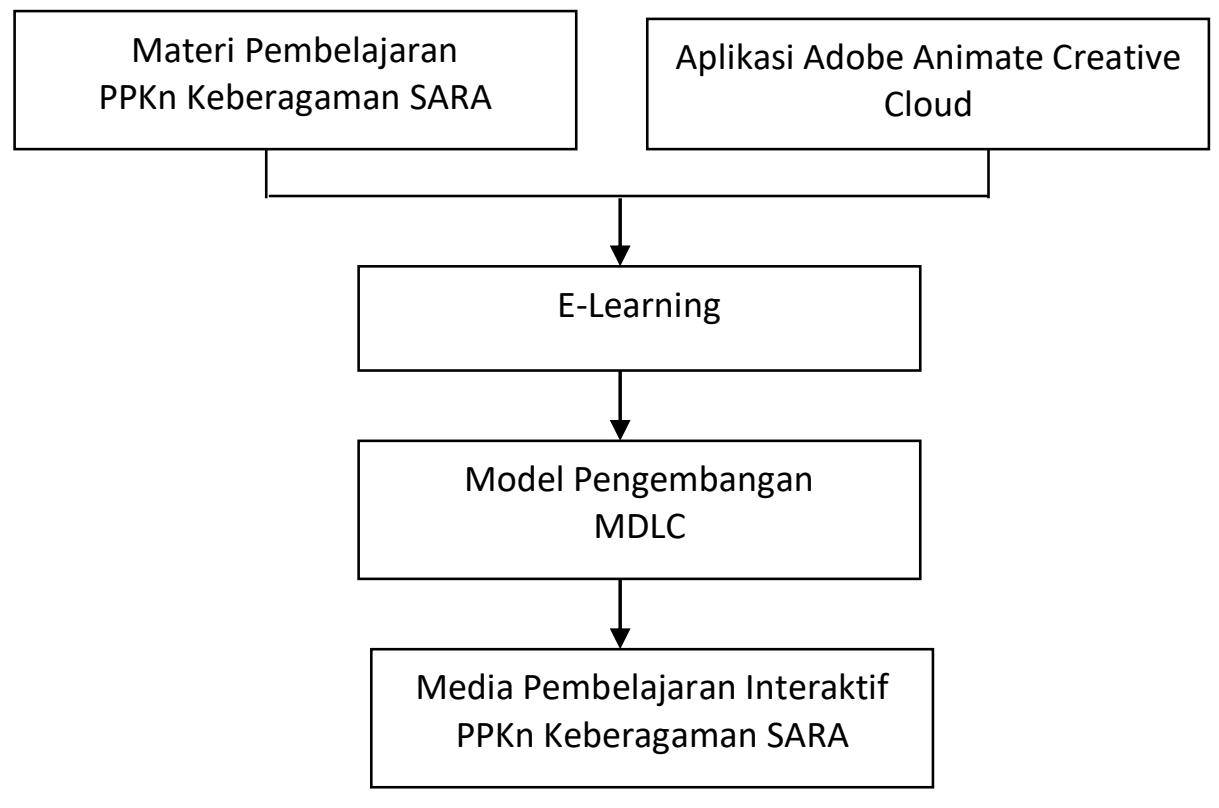

Gambar 1. Kerangka Pemikiran

\section{KAJIAN PUSTAKA}

\section{Metode Multimedia Development Life Cycle (MDLC)}

Penelitian pengembangan adalah upaya untuk menghasilkan suatu produk berupa materi, modul, alat dan atau strategi pembelajaran yang digunakan untuk mengatasi 
pembelajaran di kelas/laboratorium, dan bukan untuk menguji teori. ${ }^{1}$ Penelitian ini memiliki tujuan mengembangkan sebuah media pembelajaran yang lebih menarik dan efisien menggunakan Aplikasi Adobe Animate Creative Cloud. Maka metode yang digunakan adalah Multimedia Development Life Cycle (MDLC), menurut Luther (dalam Sutopo, 2012: 32) metode ini memiliki 6 tahapan yang harus dilalui, yaitu 1) concept, 2) design, 3) material collecting, 4) assembly, 5) testing, dan 6) distribution. Dari keenam tahap tersebut dapat dipahami melalui gambar diagram berikut:

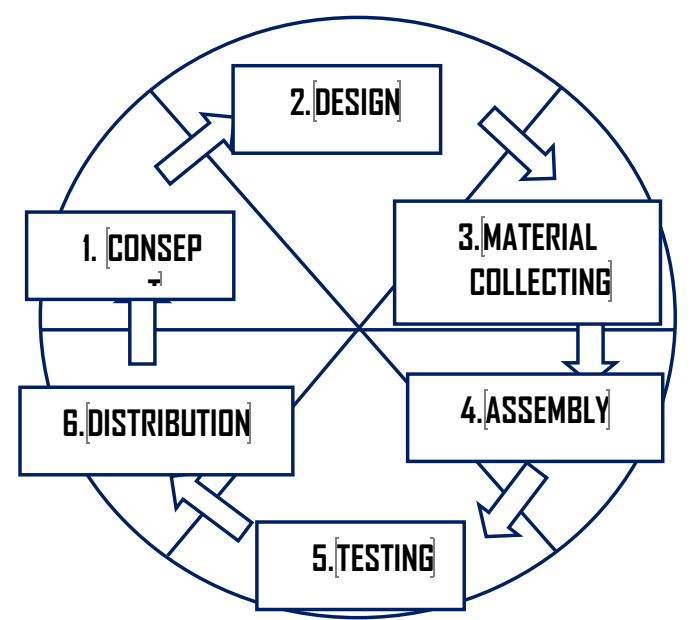

Gambar 2. Diagram Multimedia Development Life Cycle.

\section{Concept}

Concept merupakan tahap awal dari metode MDLC, pada tahap ini mulai ditentukan tujuan dan pengguna media pembelajaran interaktif yang akan dibuat. Jadi pada tahap ini perlu dipahami terlebih dahulu siapa saja penggunanya dan tujuan dibuatnya media pembelajaran interaktif tersebut, agar ketika media pembelajaran ini dapat dimanfaatkan secara efisien dan tepat guna.

\section{Design}

Tahap design menjelaskan tentang hal-hal yang dilakukan dan bagaimana proyek media pembelajaran dengan menggunakan aplikasi Adobe Animate Creative Cloud tersebut akan dibuat. Pembuatan tampilan visual, navigasi serta proses desain media secara lengkap.

\section{Material Collecting}

Tahap ini merupakan proses untuk pengumpulan segala sesuatu yang dibutuhkan dalam pembuatan media pembelajaran interaktif, semua bahan yang dibutuhkan untuk

${ }^{1}$ Setiadi, Gatut, and Nurma Yuwita. "PENGEMBANGAN MODUL MATA KULIAH BAHASA INDONESIA MENGGUNAKAN MODEL ADDIE BAGI MAHASISWA IAI SUNAN KALIJOGO MALANG”. Akademika : Jurnal Manajemen Pendidikan Islam 2, no. 2 (December 3, 2020): 200-217. Accessed May 17, 2021.

https://ejournal.iaiskjmalang.ac.id/index.php/akad/article/view/207. 
pembuatan media pembelajaran interaktif ini dikumpulkan. Karena media pembelajaran ini dibuat dengan menggunakan sarana komputer, maka bahan yang dibutuhkan mayoritas berupa file-file multimedia seperti audio dan gambar yang akan didesain hingga menjadi media pembelajaran interaktif yang sesuai dengan kebutuhan pembelajaran PPKn kelas VII SMP/MTs tentang keberagaman SARA.

\section{Assembly}

Tahap ini semua objek atau bahan multimedia yang telah terkumpul mulai dibuat menjadi sebuah media pembelajaran interaktif. Pembuatan media ini didasarkan pada flowchart yang sudah dirancang. Berbagai materi serta file-file multimedia tersebut kemudian dirangkai dan disusun sesuai desain yang dibuat. Untuk merangkai dan menyusun menjadi media pembelajaran maka digunakan aplikasi Adobe Animate Creative Cloud.

\section{Testing}

Setelah proyek pembuatan media pembelajaran interaktif ini telah selesai dibuat, maka perlu diadakan pelaksanaan uji coba. Hal ini dimaksudkan agar media pembelajaran interaktif yang telah dibuat sebelumnya memang tepat dan sesuai, sebelum dapat diterapkan dalam pembelajaran secara umum.

\section{Distribution}

Tahap akhir dari metode MDLC adalah distribution, pada tahap ini media pembelajaran interaktif yang telah memiliki nilai kelayakan baik dan sesuai untuk digunakan sebagai media pembelajaran akan digandakan dan disebarkan kepada pengguna yakni diberikan kepada peserta didik dan guru pengajar di sekolah tersebut.

\section{Media Pembelajaran Interaktif}

Multimedia menjadi dasar untuk membuat media pembelajaran interaktif. Arsyad (2011: 171) menyebutkan bahwa "multimedia interaktif adalah berbagai macam kombinasi gabungan antara grafik, teks, suara, video, dan animasi. Penggabungan ini merupakan satu kesatuan yang secara bersama-sama menampilkan informasi, pesan atau isi pelajaran". Berdasarkan pendapat tersebut dapat dipahami bahwa media pembelajaran interaktif yang mengacu pada multimedia terbentuk melalui gabungan antara grafik, teks, suara, video, dan animasi yang dirancang dengan menggunakan sebuah aplikasi tertentu seperti Adobe Animate Creative Cloud. 


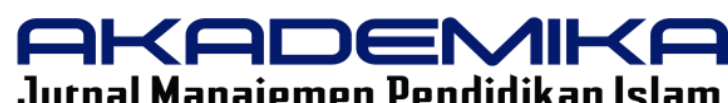

Jurnal Manajemen Pendidikan Islam

INSTITUT AGAMA ISLAM SUNAN KALIJOGO MALANG

P-ISSN 2622-9293 / E-ISSN 2721-9658

Volume 3 Nomor 1 Juni 2021

Ariani dan Haryanto (2010: 27) menguraikan karakteristik media pembelajaran interaktif antara lain: (1) memiliki lebih dari satu media yang konvergen, misalnya menggabungkan unsur audio dan visual; (2) bersifat interaktif, dalam pengertian memiliki kemampuan untuk mengakomodasi respon pengguna; (3) memiliki sifat mandiri, artinya memberi kemudahan dan kelengkapan isi sedemikian rupa sehingga pengguna dapat menggunakan tanpa bimbingan orang lain. Dalam media pembelajaran interaktif ini memuat materi pembelajaran tentang keberagaman SARA. Kurniasih dan Sani menjelaskan tentang “Materi pembelajaran (instructional materials) adalah pengetahuan, ketrampilan, dan sikap yang harus dikuasai peserta didik dalam rangka memenuhi standar kompetensi yang ditetapkan (2014: 10).

\subsection{Aplikasi Adobe Animate Creative Cloud}

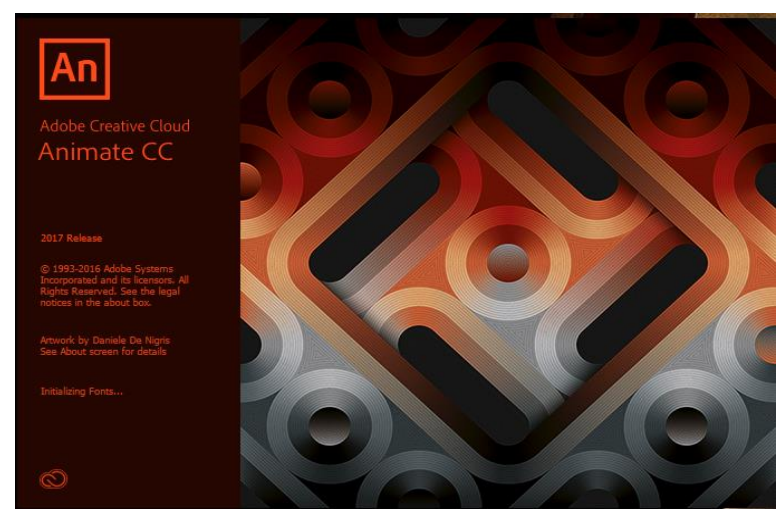

Gambar 3. Tampilan Awal Adobe Animate Creative Cloud 2017

Adobe Animate Creative Cloud merupakan gabungan konsep pembelajaran dengan teknologi audiovisual yang mampu menghasilkan fitur-fitur baru yang dapat dimanfaatkan dalam pendidikan. Pembelajaran berbasis multimedia tentu dapat menyajikan materi pelajaran yang lebih menarik, tidak monoton, dan memudahkan penyampaian. Peserta didik dapat mempelajari materi pelajaran tertentu secara mandiri dengan komputer yang dilengkapi program multimedia.

Berbagai keunggulan yang ada dalam aplikasi Adobe Animate Creative Cloud, memungkinkan penggunaan Adobe Animate Creative Cloud untuk digunakan dalam dunia pendidikan, salah satu pemanfaatannya adalah sebagai media pembelajaran, dengan merancangnya hingga sesuai dengan bahan ajar yang akan disampaikan kepada peserta didik.

\section{METODE}




\section{Pendekatan dan Metodologi Penelitian}

Menurut Suriasumantri dalam Kriyantono (2010: 49) pendekatan adalah falsafah yang mendasari suatu metodologi penelitian. Pendekatan dalam penelitian MDLC dalam media keberagaman SARA menggunakan aplikasi Adobe Animate Creative Cloud adalah pendekatan interpretatif. Penelitian ini menggunakan pendekatan interpretif (subjektif). Ilmu sosial Interpretif berkaitan dengan cara orang berinteraksi dan hidup akur satu sama lain, anatara guru dan murid. Secara umum, pendekatan interpretatif adalah analisis sistematis mengenai aksi sosial yang bermakna melalui observasi manusia secara terperinci dan langsung dalam latar alamiah, supaya bisa memperoleh pemahaman dan interpretasi mengenai cara orang menciptakan dan mempertahankan dunia sosial mereka (Neuman, 2013, h.114). Metodologi yang digunakan adalah kualitatif.

\section{Jenis Penelitian}

Peneliti menggunakan jenis penelitian deskriptif karena penelitian ini bertujuan membuat deskripsi secara sistematis, faktual, dan akurat tentang fakta-fakta dan sifat-sifat populasi atau objek tertentu (Kriyantono, 2010: 69). Laporan penelitian akan berisi kutipankutipan data untuk mencari gambaran penyajian laporan. Data tersebut mungkin berasal dari naskah wawancara, catatan lapangan, foto, video tape, dokumen pribadi, catatan atau memo, dan dokumen resmi lainnya (Moleong, 2014: 14). Penelitian ini membahas tentang pengembangan e-learning menggunakan aplikasi Adobe Animate Creative Cloud dengan metode MDLC.

\section{Data dan Sumber Data}

Media pembelajaran interaktif menggunakan aplikasi Adobe Animate Creative Cloud ini bertujuan untuk memudahkan proses penyampaian materi pelajaran tentang keberagaman SARA. Jadi yang menjadi data dalam penelitian pengembangan media pembelajaran interaktif ini adalah berbagai informasi yang berkaitan dengan kebutuhan siswa dan guru terhadap media pembelajaran interaktif keberagaman SARA.

Sumber data yang digunakan untuk memperoleh data kebutuhan media pembelajaran interaktif keberagaman SARA adalah guru dan siswa. "Kata-kata dan tindakan orang-orang yang diamati atau diwawancarai merupakan sumber data utama" (Moleong, 2014: 157).

\section{Metode Pengumpulan Data}

Metode pengumpulan data merupakan cara peneliti untuk memperoleh data yang dibutuhkan dalam penelitian, sehingga data yang didapat adalah benar-benar data yang valid 
dan reliabel. Riduwan mendefinisikan bahwa " Metode pengumpulan data ialah teknik atau cara-cara yang dapat digunakan oleh peneliti untuk mengumpulkan data (2013: 97). Metode pengumpulan data bisa dilakukan melalui wawancara, observasi, dan dokumentasi.

\section{Teknik Analisis Data}

Data yang telah peneliti peroleh akan dianalisis dengan model yang telah ditawarkan oleh Miles dan Huberman. Menurut Sugiyono (2012: 246) aktifitas dalam analisis data yaitu: data reduction, data display, dan data conclusion drawing/verification.

\section{Keabsahan Data}

Menurut Moleong (2014: 324) untuk menetapkan keabsahan (trustworthiness) data diperlukan teknik pemeriksaan. Pelaksanaan teknik pemeriksaan didasarkan atas sejumlah kriteria tertentu. Ada empat kriteria yang digunakan, yaitu derajat kepercayaan (credibility), keteralihan (transferability), kebergantungan (dependability), dan kepastian (confirmability).

\section{HASIL DAN PEMBAHASAN}

\section{Analisis Kebutuhan Media Pembelajaran Interaktif}

Media pembelajaran interaktif keberagaman SARA sebuah media yang ditujukan penggunaannya untuk peserta didik kelas VII di SMP Bhinneka Tunggal Ika pada mata pelajaran PPKn. Agar pengembangan media pembelajaran interaktif ini dapat tepat guna ketika digunakan dalam pembelajaran yang dilaksanakan, maka perlu dilaksanakan observasi untuk mengetahui sarana dan prasarana yang ada di sekolah, serta analisis kebutuhan peserta didik dan guru terlebih dahulu. Hasil dari observasi ini adalah data awal yang digunakan untuk merancang sebuah media pembelajaran interaktif yang akan digunakan di sekolah tersebut.

\section{Mengindentifikasi karateristik peserta didik.}

Dalam pengembangan media pembelajaran menggunakan Adobe Animate Creative Cloud diperlukan analisis pengguna, hal ini bertujuan agar mengetahui bagaimana sifat ataupun karatkteristik peserta didik pada saat melaksanakan proses belajar. Dengan memahami karakteristik peserta didik pada saat melaksanakan proses pembelajaran, maka peneliti akan dapat mengembangkan media pembelajaran interaktif yang sesuai untuk digunakan oleh peserta didik tersebut sehingga dapat meningkatkan kompetensinya. Berikut 
ini data persentase peserta didik pada kelas VII A SMP Bhinneka Tunggal Ika yang akan menjadi pengguna media pembelajaran interaktif keberagaman SARA.

Tabel 1. Persentase peserta didik kelas VII A SMP Bhinneka Tunggal Ika Jenis Kelamin

\begin{tabular}{|ll|l|l|l|l|}
\hline & & Frequency & Percent & Valid Percent & Cumulative Percent \\
\hline Valid & Laki-Laki & 19 & 52,8 & 52,8 & 52,8 \\
& Perempuan & 17 & 47,2 & 47,2 & 100,0 \\
& Total & 36 & 100,0 & 100,0 & \\
\hline
\end{tabular}

Berdasarkan tabel tersebut diketahui jumlah peserta didik laki-laki berjumlah 19 orang dan perempuan 17 orang, dengan persentase laki-laki 57,78\% dan perempuan 47,22\%, jadi peserta didik laki-laki lebih banyak 2 orang atau 5,56\% dibandingkan peserta didik perempuan.

\section{Mengindentifikasi Kebutuhan Komputer untuk Media Pembelajaran Interaktif Keberagaman SARA}

Untuk menggunakan media pembelajaran interaktif teks cerita fantasi dalam proses pembelajaran, maka dibutuhkan sebuah sarana komputer yang memiliki tingkat spesifikasi yang layak, agar media tersebut dapat digunakan dengan maksimal.

SMP Bhinneka Tunggal Ika memiliki sebuah laboratorium komputer dengan jumlah komputer sebanyak 30 unit. Tiap unit komputer telah memiliki spesifikasi di atas spesifikasi minimum yang dibutuhkan untuk menjalankan media pembelajaran interaktif keberagaman SARA. Tingkat spesifikasi komputer di SMP Bhinneka Tunggal Ika adalah seperti data berikut:

(a) Kecepatan prosesor Dual Core 1,8 Ghz

(b) operating system Windows menggunakan windows 7, windows 8.0 dan 8.1

(c) 2 GB RAM,

(d) 250 GB Hard Drive space

(e) 64-bit monitor warna LED 20 inch yang bisa menampilkan resolusi 1336 x 768 resolution

(f) CD-ROM drive. 
Dengan memanfaatkan sarana komputer yang sesuai tersebut maka media pembelajaran interaktif dapat digunakan oleh peserta didik dan guru dalam proses pembelajaran untuk mempermudah tercapainya tujuan pembelajaran.

\section{Mengindentifikasi tujuan media pembelajaran interaktif}

Berdasarkan analisis karakteristik dan analisis sarana, maka tujuan pengembangan media pembelajaran interaktif menggunakan aplikasi Adobe Animate Creative Cloud adalah mengembangkan media pembelajaran interaktif dengan materi pokok keberagaman SARA yang berfungsi sebagai media pendukung dalam proses pembelajaran dan dapat digunakan oleh guru mata pelajaran PPKn dan peserta didik kelas VII, sehingga dengan menggunakan media pembelajaran interaktif tersebut dapat meningkatkan kompetensi peserta didik. Untuk lebih memahami tentang kebutuhan terhadap media pembelajaran interaktif, maka digunakan juga penyebaran angket terhadap peserta didik dan guru PPKn

\section{Inovasi Media Pembelajaran Interaktif dengan Menggunakan Aplikasi Adobe Animate} Creative Cloud

Inovasi media pembelajaran interaktif dengan menggunakan aplikasi adobe animate creative cloud merupakan salah satu inovasi dari perkembangan teknologi pembelajaran interaktif. Penjabaran dari tiap tahap pengembangan media ini adalah sebagai berikut:

Media pembelajaran interaktif merupakan media pembelajaran yang memanfaatkan suatu aplikasi tertentu untuk mendesain dan membuatnya. Dalam penelitian ini aplikasi yang digunakan untuk mengembangkan suatu media pembelajaran interaktif adalah Adobe Animate Creative Cloud (CC)2017. Selain itu agar mendapatkan hasil yang baik juga digunakan aplikasi pendukung yaitu: 1) Adobe Photoshop Creative Cloud (CC)2017 untuk mengedit dan mendesain gambar background dan tombol, 2) aplikasi Exe-learning yang digunakan untuk menyusun bahan ajar berupa E-Book dan aplikasi flip book untuk membuat bahan ajar berbentuk flip book, bahan ajar tersebut dimasukkan dalam media pembelajaran interaktif sebagai materi pendukung.

Materi dalam media interaktif ini mengacu pada kurikulum 2013 yakni tentang keberagaman SARA pada kelas VII SMP/MTs. Penelitian pengembangan dilaksanakan dengan subjeknya adalah peserta didik kelas VII SMP Bhinneka Tunggal Ika di Desa Sengonagung Kabupaten Pasuruan. Dikembangkannya media pembelajaran bertujuan agar dapat mengembangkan kompetensi peserta didik berkaitan dengan keberagaman SARA dan juga untuk menumbuhkan minat belajar peserta didik pada mata pelajaran PPKn. 


\section{QR \\ Jurnal Manajemen Pendidikan Islam}

INSTITUT AGAMA ISLAM SUNAN KALIJOGO MALANG

P-ISSN 2622-9293 / E-ISSN 2721-9658

Volume 3 Nomor 1 Juni 2021

Media pembelajaran interaktif dimulai dengan halaman pembuka pertama yang menampilkan judul, kemudian menuju halaman pembuka kedua yang memuat tentang kalimat pesan. Setelah itu masuk pada halaman pendahuluan yang berisi tentang contoh profil penulis terkenal untuk memotivasi peserta didik dalam mempelajari teks keberagaman SARA. Selanjutnya baru masuk ke menu utama, pada menu utama ini terdiri dari empat sub menu utama yang terdapat pada menu utama awal, sub menu tersebut antara lain: (1) Kompetensi Dasar, (2) Bahan Ajar, (3) Soal Latihan, dan (4) Materi pendukung. Untuk lebih jelasnya berikut ini garis besar tampilan dari media pembelajaran interaktif keberagaman SARA.

\section{Tampilan Awal}

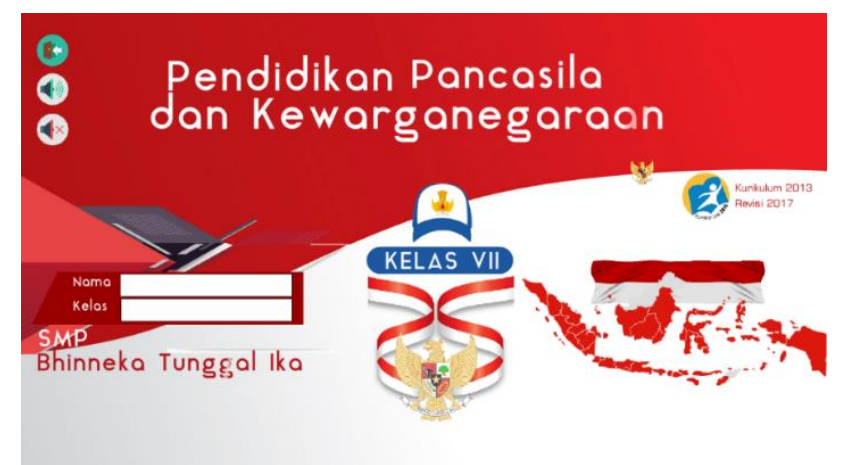

Gambar 4. Tampilan pembuka pertama

Tampilan pembuka pertama ini berisi judul media pembelajaran interaktif dan gambar animasi sederhana untuk menarik perhatian peserta didik.

\section{Tampilan Menu Utama}

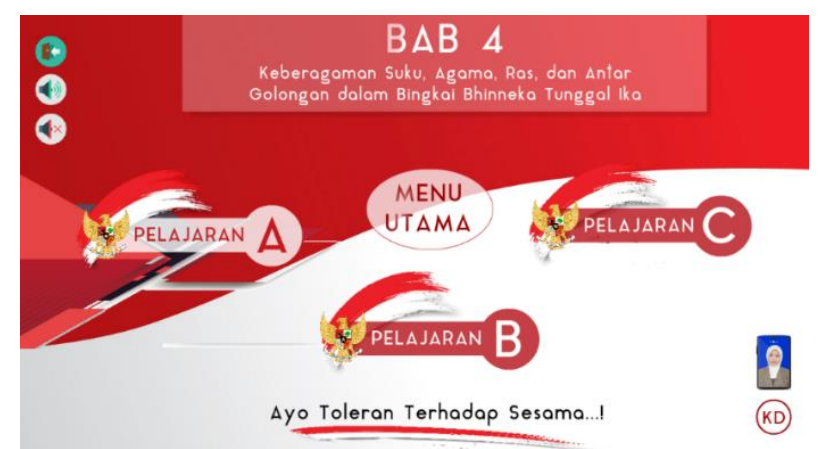

Gambar 5. Tampilan Menu Utama

Pada menu utama terdapat sub menu yang dapat dipilih oleh peserta didik atau guru sebagai pengguna, isi dalam tiap sub menu tersebut disesuaikan dengan Kompetensi Dasar dan tujuan pembelajaran tentang teks keberagaman SARA kelas VII SMP/MTs. 


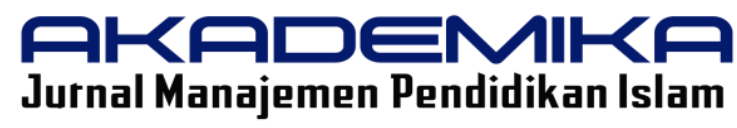

INSTITUT AGAMA ISLAM SUNAN KALIJOGO MALANG

P-ISSN 2622-9293 / E-ISSN 2721-9658

Volume 3 Nomor 1 Juni 2021

\section{Kompetensi Dasar}

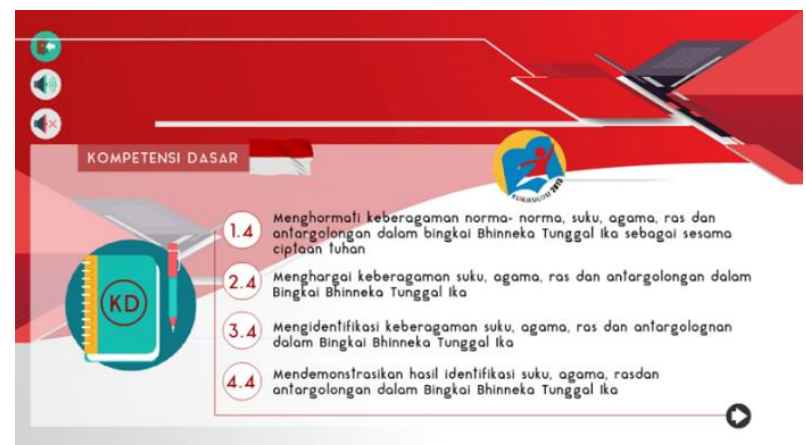

Gambar 6. Tampilan Kompetensi Dasar

Menu pada Kompetensi Dasar (KD) ini berisi tentang empat KD yaitu dua KD pengetahuan dan dua KD keterampilan, yang semuanya menjadi dasar dalam materi teks cerita fantasi. Dari keempat KD tersebut dirumuskan empat tujuan pembelajaran yang ingin dicapai melalui media pembelajaran interaktif ini.

\section{Bahan Ajar}

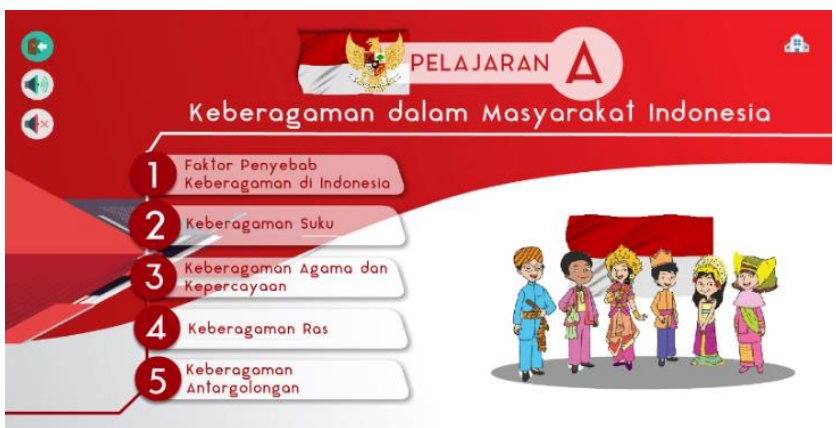

Gambar 7. Pelajaran A

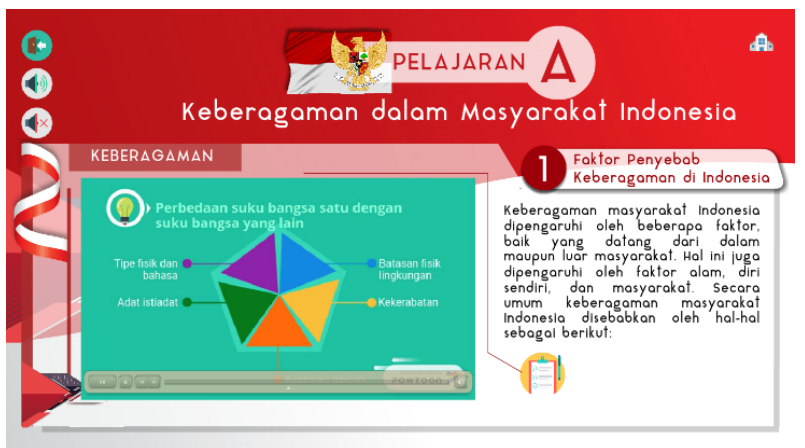

Gambar 8. Pelajaran A 


\section{คКคDЕMIKค \\ Jurnal Manajemen Pendidikan Islam}

INSTITUT AGAMA ISLAM SUNAN KALIJOGO MALANG

P-ISSN 2622-9293 / E-ISSN 2721-9658

Volume 3 Nomor 1 Juni 2021

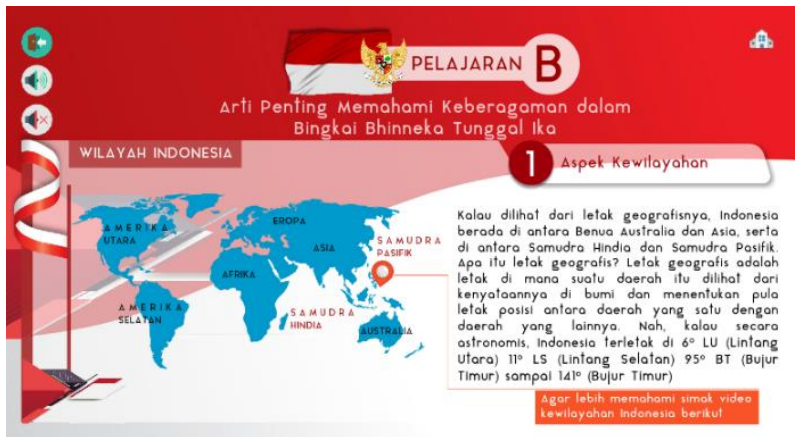

Gambar 9. Pelajaran B

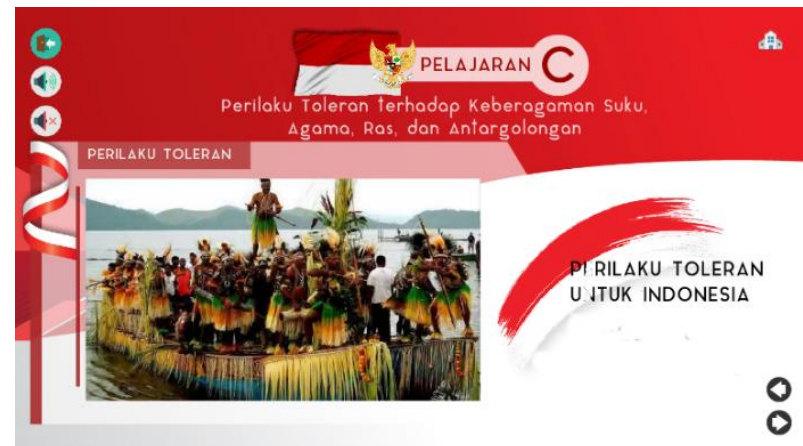

Gambar 10. Pelajaran C

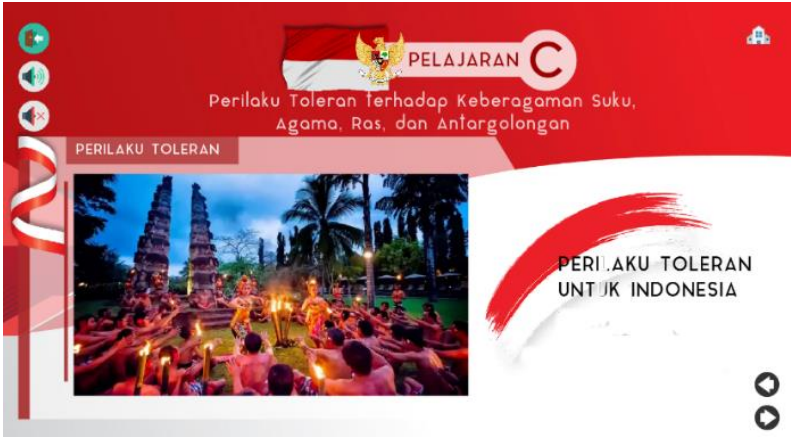

Gambar 11. Pelajaran C

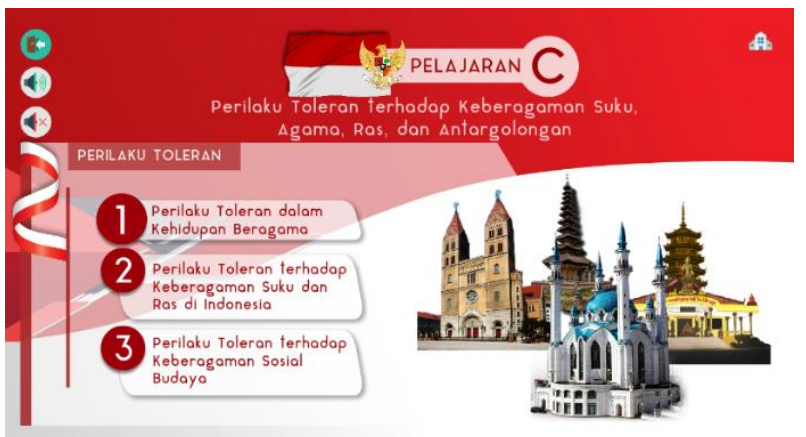


Gambar 12. Pelajaran $C$

Tampilan Akhir Media Pembelajaran Interaktif

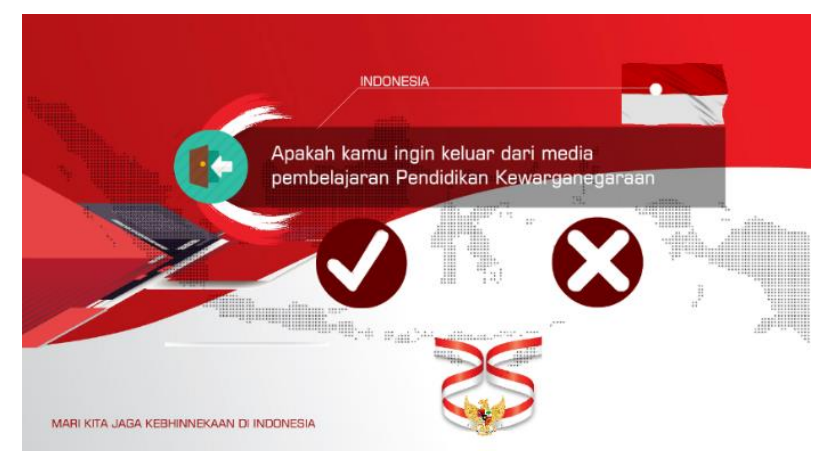

Gambar 13. Tampilan Akhir Media Pembelajaran Interaktif

Media pembelajaran ini pada tampilan akhirnya diberikan kalimat berupa kalimat ucapan selamat, dan juga kalimat motivasi untuk peserta didik.

Berikut ini keterangan berkaitan dengan produk tersebut :

(1) Media Pembelajaran Interaktif ini didesain dengan mengambil tema future $H U D$, yakni tampilan yang mayoritas dibuat transparansi dengan desain futuristik.

(2) Isi dalam media ini adalah berkaitan dengan materi teks keberagaman SARA kelas VII tingkat SMP/MTs mata pelajaran PPKn Kurikulum 2013.

(3) Terdapat soal latihan dalam bentuk uraian pada tiap sub materi pada akhir media pembelajaran interaktif.

(4) Produk akhir dari media pembelajaran interaktif ini dikemas dalam bentuk CD karena hasil akhir media pembelajaran interaktif ini adalah file berformat aplication (.exe).

\section{Pengembangan Media}

Media pembelajaran interaktif ini dirancang dengan menggunakan metode pengembangan Multimedia Development Life Cycle (MDLC) yang memiliki 6 tahapan. Penjabaran dari tiap tahap pengembangan media ini adalah sebagai berikut:

\section{Concept}

Dalam tahap ini ada dua hal yang perlu diperhatikan, antara lain:

1) Menentukan tujuan pembuatan media yaitu:

(a) menumbuhkan minat belajar peserta didik dalam pembelajaran PPKn di kelas VII SMP/MTs pada materi keberagaman SARA,

(b) guru dapat menyampaikan materi pembelajaran dengan mudah.

2) Menentukan pengguna media pembelajaran interaktif 
Pengguna media pembelajaran interaktif keberagaman SARA ini adalah:

(a) Guru PPKn kelas VII SMP Bhinneka Tunggal Ika,

(b) Peserta didik kelas VII SMP Bhinneka Tunggal Ika.

\section{Design}

Tahapan design pada media pembelajaran interaktif ini dilakukan melalui beberapa tahap yaitu:

1) Merancang materi pembelajaran

Materi dalam media ini tentang keberagaman SARA kelas VII SMP/MTs kurikulum 2013 revisi 2017.

2) Merancang desain media pembelajaran menggunakan program aplikasi Adobe Animate Creative Cloud.

Bentuk desain media pembelajaran interaktif keberagaman SARA menggunakan aplikasi Adobe Animate Creative Cloud terdiri dari tiga desain rancangan yaitu: (a) Diagram use case, (b) Perancangan menu, (c) Storyboard

\section{Material Collecting}

Tahap ini merupakan proses untuk pencarian dan pengumpulan segala sesuatu yang dibutuhkan dalam pembuatan media pembelajaran interaktif, semua bahan yang dibutuhkan dan dikumpulkan untuk pembuatan media ini.

\section{Assembly}

Tahap ini semua objek atau bahan multimedia mulai dibuat menjadi media pembelajaran. Pembuatan media pembelajaran didasarkan pada flowchart yang sudah dirancang. Berbagai materi teks cerita fantasi sefta file-file multimedia yang telah diperoleh kemudian dirangkai dan disusun menggunakan aplikasi Adobe Animate Creative Cloud (CC) 2017.

\section{Testing (Uji Coba)}

Uji coba dilakukan dengan menerapkan hasil dari proyek media pembelajaran tersebut pada pembelajaran kelas kecil sebanyak 10 peserta didik, dan guru mata pelajaran PPKn sebagai pengguna media pembelajaran interaktif ini. Dalam pengujian media pembelajaran ini dilakukan pengecekan terhadap kemudahan dalam mengoperasikan dan memahami berbagai hal yang ada dalam media pembelajaran tersebut.

\section{Distribution}


Pada tahap ini media pembelajaran interaktif akan digandakan dan dikemas dalam bentuk DVD yang di dalamnya berisi semua file media pembelajaran interaktif. DVD media pembelajaran interaktif teks cerita fantasi tersebut akan diberikan kepada pengguna yakni untuk peserta didik kelas VIIA SMP Bhinneka Tunggal Ika yang berjumlah 36 orang dan satu orang guru PPKn di sekolah tersebut.

\section{DAFTAR PUSTAKA}

Ariani, Niken dan Dany Haryanto. 2010. Pembelajaran Multimedia di Sekolah. Jakarta: Prestasi Pustakarya.

Arsyad, A. 2011. Media Pembelajaran, cetakan ke-15. Jakarta: PT Raja Grafindo Persada.

Kurniasih, Imas \& Sani, Berlin. 2014. Implementasi Kurikulum 2013 Konsep \& Penerapan. Surabaya: Kata Pena.

Kriyantono, Rachmat. 2010. Teknik Praktis Riset Komunikasi. Jakarta: Kencana.

Moelong, Lexy J. 2014. Metode Penelitian Kualitatif. Bandung: PT Remaja Rosdakarya.

Neuman, Lawrence. 2013. Metodologi Penelitian Sosial: Pendekatan Kualitatif dan Kuantitatif, Edisi 7. Terjemah oleh Edina T. Sofia. Jakarta: PT Indeks.

Riduwan. 2013. Metode Penelitian Kombinasi. (cetakan ke-9). Bandung. Alfabeta.

Setiadi, Gatut, and Nurma Yuwita. "PENGEMBANGAN MODUL MATA KULIAH BAHASA INDONESIA MENGGUNAKAN MODEL ADDIE BAGI MAHASISWA IAI SUNAN KALIJOGO MALANG". Akademika : Jurnal Manajemen Pendidikan Islam 2, no. 2 (December 3, 2020): 200-217. Accessed May 17, 2021. https://ejournal.iaiskjmalang.ac.id/index.php/akad/article/view/207.

Sugiyono. 2012. Metode Penelitian Kuantitatif, Kualitatif, dan R\&D. Bandung: Alfabeta.

Sutopo, Ariesto Hadi.. 2012. Teknologi Informasi dan Komunikasi dalam Pendidikan. Yogyakarta: PT Graha Ilmu.

Vaughan, Tay. 2011. Multimedia: Making it work. Eighth Edition. New York: Technology Education Mac Grow Hill 